\title{
Role of Orexin System in Obesity
}

Giovanni Messina', Vincenzo Monda1, Fiorenzo Moscatelli',3, Anna A. Valenzano², Giuseppe Monda', Teresa Esposito', Saverio De Blasio', Antonietta Messina ${ }^{1}$, Domenico Tafuri ${ }^{4}$, Maria Rosaria Barillari ${ }^{5}$, Giuseppe Cibelli ${ }^{2}$, Sergio Chieffi ${ }^{1}$, Bruno Varriale ${ }^{1}$ and Marcellino Monda ${ }^{1 *}$

${ }^{1}$ Department of Experimental Medicine, Section of Human Physiology and Clinical Dietetic Service, Second University of Naples, 16 Costantinopoli Str., 80100 Naples, Italy ${ }^{2}$ Department of Clinical and Experimental Medicine, University of Foggia, 1 L. Pinto Avenue, 71122 Foggia, Italy

${ }^{3}$ Department of Human Movement and Sport Sciences, University of Rome "Foro Italico", 00135 Rome, Italy

${ }^{4}$ Department of Motor Sciences and Wellness, University of Naples "Parthenope", 40 Medina Str., 80100 Naples, Italy

${ }^{5}$ Division of Audiology and Phoniatrics, Second University of Naples (SUN) via L. De Crecchio,3,80138, Naples, Italy

\begin{abstract}
Obesity is a public health disease and its incidence is steadily increasing both in adults and in children especially in the Western World. It is important to understand the underlying mechanisms of obesity and possible treatments as the orexin system with its receptors, which are involved in different physiological processes. In fact, the aim of this mini-review is to consider the importance of the orexin system and the role that orexin plays in the regulation of obesity and physical activity. Furthermore to demonstrate how the orexin and its receptors fit within a network distributed in multiple brain areas, each with specific actions, whose activation and interconnection has been seen to lead to a lower propensity for increase of fat mass, it could thus constitute an important future target for prevention and treatment of obesity.
\end{abstract}

\section{Keywords: Orexin; Obesity; Energy expenditure}

\section{Introduction}

The orexin (hypocretin) is an important neurotransmitter in the regulation of sleep-wakefulness and appetite. There are two types of orexin peptides: the orexin-A (OXA or hypocretin 1) and orexin-B (OXB or hypocretin 2). The majority of the orexin peptides are synthesized in neurons located in the lateral and back hypothalamus and they send projections throughout the brain regions [1,2]. These peptides derive from the prepro-orexin (prepro hypocretin) gene, which encodes a precursor (130 amino acids in rodents, 131 residues in humans) that is cleaved into orexin-A (synonymous with hypocretin-1; 33 amino acids) and orexin-B (hypocretin-2; 28 residues (Figure 1).

The orexin binds to two types of receptors, belonging to the class of $\mathrm{G}$ protein-coupled receptors: orexin receptor type-1 (OX1R or hypocretin receptor 1$)$ and orexin receptor type-2 (OX2R or hypocretin receptor 2) Both orexin receptors subtypes can bind to OXA and OXB, but with differential affinity; in particular orexin receptor type-1 has a higher affinity for OXA, while orexin receptor type- 2 has equal affinity for either orexin peptide [3,4] (Figure 1).

Orexin neurons have a lot of projections related to many and different brain regions, as well as for the orexin receptors that are expressed in several areas of the brain [1,2]. A similar distribution of orexin neurons and their receptors explains how these neurotransmitters are involved in numerous physiological processes, including the modulation of the sleep, the arousal and of the energy expenditure, suggesting an important role in development of obesity [5-8] (Figure 2). In this review we want to highlight that the orexin system can lead to an increase in energy expenditure and so give a contribute to the obesity resistance. We want to provide a synthesis of the current state of knowledge in the regulation of hypothalamic orexin during obesity and provide a platform on which to develop an improved clinical outcomes during obesity in relation to the autonomic nervous system, brown adipose tissue, sleep-wake rhythm, expenditure energy.

The way of the action of the orexin system depends on a series of signals to multiple brain regions, and it is extremely important to understand the anatomy and function of the neuronal network of orexin system. The proof of the fact the orexins peptides are involved into energy metabolism is exemplified in a mouse model that exhibits postnatal loss of orexin neurons [5]. In these mice, the orexin promoter drives expression of the neurodegenerative gene ataxin-3 and leading to progressive loss of the orexin neurons during development. These mice show hypophagia, lower levels of spontaneous physical activity (SPA) and express the appearance of a obesity state when fed a regular diet $[5,8,9]$. This indicates that an important function of the orexins peptides is to rule energy expenditure and so modulate food intake. A further support for this idea comes from other mouse models in which the results prove that these mice show resistance to high-fat diet-induced obesity, corroborating with the role of orexin in promoting energy expenditure [10,11].

\section{Orexin System and Neural Network}

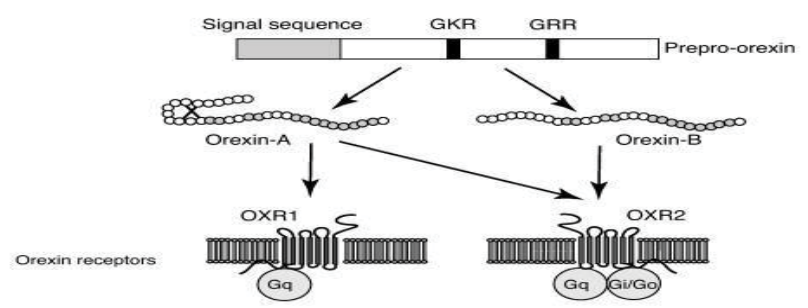

Figure 1: Composition of Orexin-A and Orexin-B. OX1R: orexin receptor type1. OX2R: orexin receptor type-2.

*Corresponding author: Prof. Marcellino Monda, MD, Department of Experimenta Medicine, Section of Human Physiology, and Clinical Dietetic Service, Second University of Naples, Via Costantinopoli 16, 80138 Naples, Italy, Tel: +39 +81566 5804; Fax +39 +815665841; E-mail: marcellino.monda@unina2.it

Received July 21, 2015; Accepted August 31, 2015; Published September 07, 2015

Citation: Messina G, Monda V, Moscatelli F, Valenzano AA, Monda G, et al. (2015) Role of Orexin system in obesity. Biol Med (Aligarh) 7: 248. doi: 10.4172/09748369.1000248

Copyright: () 2015 Messina G, et al. This is an open-access article distributed under the terms of the Creative Commons Attribution License, which permits unrestricted use, distribution, and reproduction in any medium, provided the original author and source are credited. 
Over the location in the lateral hypothalamus, which were initially described, the orexin and its receptors have been highlighted in neuronal bodies and positive fibers present in different regions of the central nervous system (CNS) and their position is in connection with the functions performed. Therefore a lot of brain sites join in this regulatory network through a significant number of neurotransmitters (Figure 3). The functions of the orexin system are expressed in different brain regions, they control the same behaviors; in fact many of the brain sites that participate in the SPA network also participate in regulatory networks for food intake and other aspects of energy balance. Several brain regions receive orexinergic input and express the OXR and this instance suggests that the behavioral outcomes of the orexin system are due to simultaneous activation of the OXR in different brain regions connected through projections.

Orexins are produced in a particular area of the hypothalamus, including the caudal lateral hypothalamus and adjacent perifornical area [12] and, from these sites, orexin projects throughout the other areas of the brain. On the basis of anatomical predisposition appears to be valid the hypothesis that the effects of the action of the orexin system derive from a series of parallel signals that come from different brain regions [13]. It is important to know that orexin neurons are in a baseline intrinsic state of depolarized activity [14] and are highly influenced by local conditions in an intralateral hypothalamic local network [15]. The Activation of the OXR causes depolarization and active neuronal firing by four possible mechanisms:

- activation of non-specific cationic currents

- activation of the $\mathrm{Na}^{+} / \mathrm{Ca}^{2+}$ exchanger

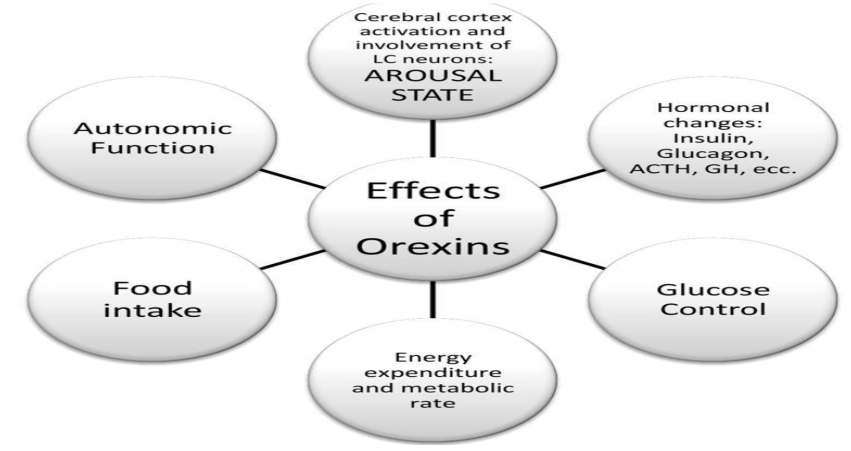

Figure 2: Effects of orexins in peripheral tissue and central nervous system. and development of obesity. Adapted from Messina et al., [8].

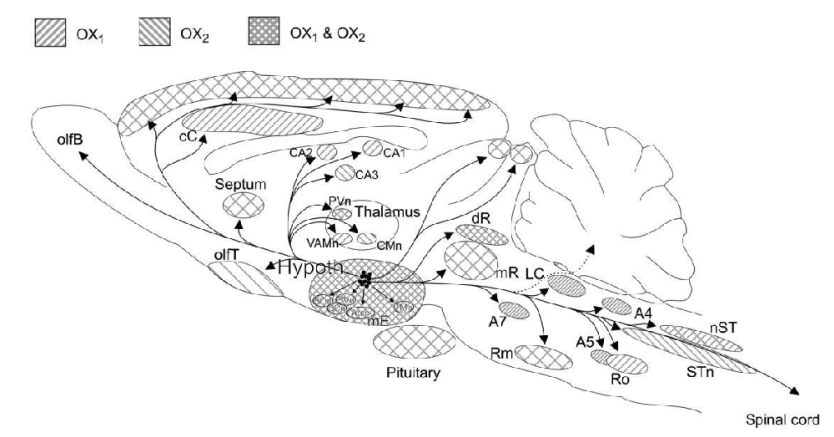

Figure 3: Brain neurotransmitters. OX1R: orexin receptor type-1. OX2R: orexin receptor type-2.
- phosphorylation-dependent inhibition of inwardly rectifying $\mathrm{K}+$ channels

- increase in $\mathrm{Ca}^{2+}$ through activation of $\mathrm{L}$ - and $\mathrm{N}$-type $\mathrm{Ca}^{2+}$ channels [16-20].

The type of mechanism appears to be cell-dependent and both orexin subtypes can couple to many G- proteins that cause neuronal depolarization through many mechanisms cell-specific (Figure 4).

\section{The Role Of Orexin In Brown Adipose Tissue Thermogenesis And Activation Of Sympathetic Nervous System}

Orexin system also influences body temperature. In fact, an Intracerebroventricular (icv) administration of orexin system induces an increase in the firing rate of the sympathetic nerves to interscapular brown adipose tissue (IBAT), accompanied with a rise in IBAT and colonic temperatures [21]. In addition, the presence of orexin receptors in many cerebral areas suggests that additional functions are played by orexin system [22]. In general, those experiments demonstrate that an icv injection of orexin system increases the temperature of IBAT, which is the most important effect or of non shivering thermogenesis in the rat [23], illustrating that the rise in heat production is also due to the activation of thermogenesis unrelated to muscle activity. IBAT activity is controlled by the sympathetic nervous system, and factors, which influence thermogenesis, appear to act centrally to modify the sympathetic outflow to IBAT [24]. The increase in colonic temperature emphasizes the effect of orexin system on the "core" temperature confirming the inclusion of orexin system among the peptides controlling body temperature. The rise of the sympathetic discharge induced by orexin system is corroborated by the increase in heart rate, although a possible reduction on the vagal tone cannot be excluded. Since Van Den Pol [25] demonstrated a direct innervation of the intermedio lateral column of spinal cord by orexin-fibers, there might be another direct pathway of the orexin induced activation of the sympathetic nervous system.

\section{Materials and Methods}

\section{Animals}

Most of the animal studies were conducted on Sprague-Dawley rats, 3 months old and weighing 250-300 g were used in the experiments. The rats were housed in pairs at controlled temperature $\left(22 \pm 1^{\circ} \mathrm{C}\right)$ and humidity $(70 \%)$ with a 12:12 h light-dark cycle with light from 07:00 to 19:00 $\mathrm{h}$. The experiments were in accordance with the European Communities Council Directive of 24 November 1986 (86/609/EEC).

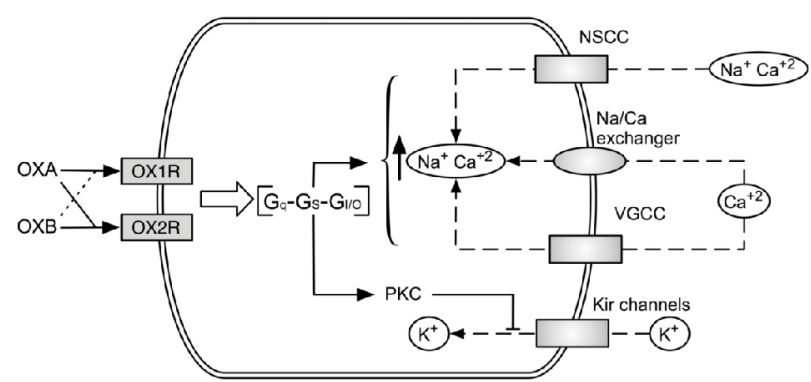

Figure 4: Neuronal depolarization. OX1R: orexin receptor type-1. OX2R orexin receptor type-2. 


\section{Apparatus}

A pair of silver wire electrodes recorded the firing rate of nerves to IBAT. The electrical pulses were amplified by a condenser-coupled amplifier and were filtered by band-pass filters (NeuroLog System, Digitimer). The raw pulses were displayed on an oscilloscope (Tektronix) and sent to a window discriminator. Square waves from the discriminator were sent to an analog-digital converter (DAS system, Keithley) and stored on a computer (Personal Computer AT, IBM) every $5 \mathrm{~s}$. A rate meter with a reset time of $5 \mathrm{~s}$ was also used to observe the time course of the nerve activity recorded by pen recorder (Dynograph, Beckman). Because signal-to-noise ratio depended on the number of nerve filaments and the condition of contact between nerve and electrodes, the basal burst rates were different for each rat. The threshold level of the event detector was fixed during the experiment at $50 \%$ of the peaks of the largest pulses and above background noise. Thermocouples (Ellab) were used to monitor colonic and IBAT temperatures (Tc and TIBAT) and the values were stored on a chart recorder.

Two electrodes applied to the forelegs monitored the heart rate (beats/min). Electrical signals were addressed to a poly- graph (Dynograph, Beckman) to record the electrocardiograph- ic activity on the card and on a computer disk

\section{Procedure}

Usually the animals were anesthetized with ip pentobarbital (50 $\mathrm{mg} / \mathrm{kg}$ bw) and a 20 -gauge stainless guide cannula was positioned stereotaxically above a lateral cerebral ventricle at the following coordinates: $1.7 \mathrm{~mm}$ lateral to the midline, $0.4 \mathrm{~mm}$ posterior to the bregma, $3.0 \mathrm{~mm}$ from the cranial theca. Nerve activity was recorded by small nerve bundles dissected from the intercostal nerves supplying the right side of IBAT. Nerve filaments were isolated from the central cut end of these nerve bundles under a dissecting microscope; the efferent activity was recorded with a pair of silver wire electrodes. The nerve filaments were covered with a mixture of vaseline and liquid petroleum at $37^{\circ} \mathrm{C}$ to avoid dehydration. At the same time as the nerve activity was recorded the heart rate, Tc and TIBAT were monitored. Tc was measured by inserting the thermocouple into the colon $4 \mathrm{~cm}$ from the anus, while TIBAT was monitored by inserting the thermocouple in the left side of IBAT. Orexin was icv injected into the cerebral ventricle in rats which had received a drug or saline alone. The drugs were delivered into the cerebral ventricle by gravity flow over a $2 \mathrm{~min}$ interval. The cannula was $0.4 \mathrm{~mm}$ longer than the guide cannula.

\section{Concept of obesity and its interindividualvariability}

Obesity (body mass index $\geq 30 \mathrm{~kg}$ of body weight $/ \mathrm{m}^{2}$ of height) is a medical condition characterized by the accumulation of excess free fat [13] that can lead negative effects on health, resulting in a reduced life expectancy and increased health problems. Obesity incidence in adults and children has increased in the last twenty years, especially in developed societies [26,27]. It is related to other diseases, including cardiovascular dysfunction, diabetes mellitus type 2, disorders of the osteo-articular system, stroke, metabolic syndrome and certain types of cancer [28]. Obesity is most commonly caused by a combination of excessive food intake, deficiency of physical activity and genetic susceptibility, enough to be considered a multifactorial disease.

The genetic component in the etiopathogenesis of obesity has assumed in last years an important role by identifying an increasing number of genes involved in the disease. The obesity in the humans can depend by different genetic factors $[29,30]$, but the major fac- tor in determining this variability is physical activity, and specifically a component of total energy expenditure known as nonexercise induced thermogenesis (NEAT) (Figure 4) [31-33]. NEAT includes all forms of energy expenditure not associated with formal exercise and it is related with the concept of spontaneous physical activity (SPA) that is utilized to describe "any type of physical activity that does not qualify as voluntary exercise" [34-42]

\section{Orexin role in sleep regulation and obesity}

Many animal studies also support the idea that disordered sleep may contribute to obesity. For example, following weight gain on a high fat diet, obese mice showed increased time spent in slow wave sleep (SWS) [43], while time spent in wakefulness was decreased and the time spent in SWS was increased especially in the dark (active) period. In this model, greater body weight was positively correlated with more time spent in SWS, and negatively correlated with time spent in wakefulness in the dark period. Obesity is associated with decreased levels of orexin [44]. Orexin system regulates and consolidates sleep/ wake patterns. Narcoleptic patients, who lack orexin, have altered sleep patterns, highly fragmented sleep and elevated body mass index [45], which highlights the importance of orexin in maintaining normal sleep/wake patterns and energy homeostasis. Thus alterations in orexin levels might be related to disordered sleep regulation observed in obese humans and animal models.

A decade ago Levin and colleagues showed that, when exposed to high fat diet, more than half of out-bred Sprague-Dawley (SD) rats developed diet-induced obesity, while the rest of the rats showed resistance to diet-induced obesity [46]. Previously we showed greater spontaneous physical activity (SPA), orexin sensitivity and orexin receptor mRNA in the lateral hypothalamus of these obesity resistant (OR) rats [47]. Relative to OR rats, SD rats had reduced orexin levels, sleep fragmentation, decreased physical activity and became obese with age [48].

Since obesity has been associated with poor sleep quality, obesity resistance might be associated with better sleep quality, characterized by consolidated sleep/wake states.

Sleep/wake patterns in ORR rats have been associated with elevated orexin receptor profiles in brain regions involved the regulation of vigilance states. In some studies have been measured $24 \mathrm{~h}$ sleep/wake patterns and orexin receptor mRNA profiles in brain sites involved in sleep regulation, in OR and normally obesity susceptible SD rats at three months of age, an age when their weight gain profiles were significantly different. Obesity resistant rats spend greater time awake primarily during the dark phase, have fewer number of and greater duration of sleep/wake episodes, less frequent transitions between different sleep/ wake states, and a lower sleep drive.

These results indicate that during the normal active period, OR rats spent more time awake and had better sleep quality than obesity susceptible SD rats. This study lends additional support to our hypothesis that increased orexin signaling in sleep/wake regulatory sites enhances sleep quality and positively influences obesity resistance.

\section{Orexin role in obesity and resting energy expenditure}

Orexin system has a primary role in relation to obesity; in fact some pharmacological studies have demonstrated that icv injections of both orexin types have increased food intake and locomotor activity [4953]. A polygenic obesity model of rats, the obesity-prone (OP) and obesity-resistant (OR) rats, derived by inbreeding from Sprague Daw- 
ley rats, has highlighted the importance of the orexin system in obesity: the results were that OR rats show higher basal levels of SPA and OXA-induced SPA after injections into the rostral lateral hypothalamic area (rLH) than OP rats [42,54-56]. Increased sensitivity to the two subtypes of orexin in OR rats is associated to an increased expression of OX1R and OX2R in the rLH compared to OP rats. It is clear that is not the only orexin to regulate body weight and amount of body fat, but also participate in the response to satiety-promoting other modulators such as leptin or insulin and thus contribute to the polygenic obesity observed in OR and OP rats; indeed the two types of rats have different weight gain profiles despite inconsistently differences in energy intake [54, 57-61]. A very important concept closely related to obesity is the energy expenditure, which is positively influenced by orexin. In general, the total energy expenditure (Total Daily Energy Expenditure) is defined by the sum of different components (Figure 5).

The energy expenditure evaluation assumes great importance because gives us the possibility to determine the nutritional and energy needs allowing to establish the energy balance, understood as caloric share necessary to maintain constant the dimension and body composition, to support physical activity daily and to ensure the long-term health.

An important consideration in energy expenditure deserves the spontaneous physical activity (SPA). It is neither a part of basal metabolism nor a part of physical exercise and was defined as a component of energy expenditure [62, 63]. Zurlo et al. [64] showed that levels of SPA are similar between relatives of the same family, could help explain propensity for weight gain in males, configuring the SPA as a hereditary trait. This idea has recently been corroborate by Levine et al., in his study showing that lean humans stand and ambulate for approximately two hours daily more than obese, which is not affected by weight loss or weight gain, in the obese and lean respectively [49]. Although great differences in body fat, energy intake and body size, OR and OP rats consume a similar number of absolute kilocalories [47]. This could mean that OR rats are less efficient in their calorie use, as they are expending a large amounts of calories to support their smaller energy needs. This supports the idea that elevated in SPA in OR rats contrib-

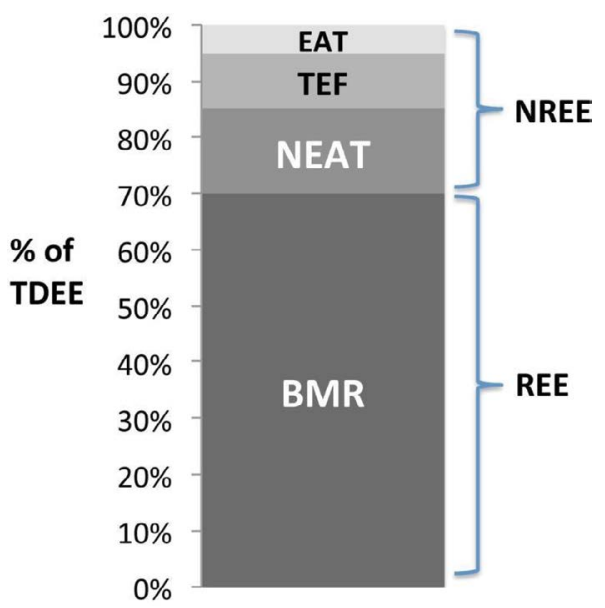

Figure 5: Components of total daily energy expenditure (TDEE). BMR=basal metabolic rate; NEAT $=$ non-exercise activity thermogenesis; $T E F=$ thermic effect of food; EAT exercise activity thermogenesis; REE=resting energy expenditure; NREE = non-resting energy expenditure. Adapted from Maclean et al. [63]. utes to their obesity resistant phenotype. Indeed, it was seen that injections of orexin A in multiple brain sites increase levels of SPA with a consequent increase of the food intake, which should lead to a condition of obesity. Instead, the activation of the orexin system increases energy expenditure and has a protective effect against obesity. To demonstrate this, has been performed studies on rats through the implantation of cannulae into RLH were given graded dose of OXA. After postinjection were measured SPA and food intake and, as expected, the result was that both components increased. At this point OR rats maintained a lean phenotype, suggesting that the negative caloric benefit of OXA-induced SPA appears to outweigh the positive calories due to OXA-induced hyperphagia. Furthermore, other studies have shown that OR rats have higher endogenous SPA and are more sensitive to other SPA-promoting stimuli and appear to be intrinsically protected from treatments that lower SPA, such as high-fat diet feeding. Then, while OP rats manifest lower SPA levels after high-fat diet consumption, OR rats maintain high basal SPA levels and have greater OXA-induced SPA after high fat diet feeding [65]. Finally, it is worth remembering that over the orexin, other neurotransmitters are able to influence SPA levels, such as cholecystokinin, corticotrophin releasing hormone and leptin, but orexin is the most consistent across all brain sites and types of stimulation.

\section{Conclusion}

Orexin system leads to an increase of energy expenditure and SPA levels. A fundamental point of this review is the evidence that higher orexin signaling provides resistance to the development of obesity and this is possible through different mechanisms like an increase in synthesis or release of orexin peptides or changes in expression of the orexin receptor. It is important to understand the concept of orexin and its role in obesity resistance to find new therapeutic and preventive solutions against the excess body weight, in fact the stimulation of orexin receptors may be a valid therapeutic approach together with appropriate low-calorie diet, frequent physical exercise and psychological proposal in order to build the foundation for preventive and curative therapy against obesity.

\section{References}

1. Date $Y$, Ueta Y, Yamashita H, Yamaguchi H, Matsukura S, et al. (1999) Orexins, orexigenic hypothalamic peptides, interact with autonomic, neuroendocrine and neuroregulatory systems. Proc Natl Acad Sci U S A 96: 748-753.

2. Tao R, Ma Z, McKenna JT, Thakkar MM, Winston S, et al. (2006) Differentia effect of orexins (hypocretins) on serotonin release in the dorsal and median raphe nuclei of freely behaving rats. Neuroscience 141: 1101-1105.

3. Sakurai T, Amemiya A, Ishii M, Matsuzaki I, Chemelli RM, et al. (1998) Orexins and orexin receptors: A family of hypothalamic neuropeptides and $\mathrm{G}$ proteincoupled receptors that regulate feeding behavior. Cell 92:573-585.

4. Ammoun S, Holmqvist T, Shariatmadari R, Oonk HB, Detheux M, et al. (2003) Distinct recognition of OX1 and OX2 receptors by orexin peptides. J Pharmacol Exp Ther 305: 507-514.

5. Hara J, Beuckmann CT, Nambu T, Willie JT, Chemelli RM, et al. (2001) Genetic ablation of orexin neurons in mice results in narcolepsy, hypophagia, and obesity. Neuron 30: 345-354.

6. Kotz CM (2006) Integration of feeding and spontaneous physical activity: role for orexin. Physiol Behav 88: 294-301.

7. Tsujino N, Sakurai $T$ (2009) Orexin/hypocretin: a neuropeptide at the interface of sleep, energy homeostasis, and reward system. Pharmacol Rev 61: 162176

8. Messina G, Dalia C, Tafuri D, Monda V, Palmieri F, et al. (2014) Orexin-A controls sympathetic activity and eating behavior. Front Psychol 5: 997.

9. Messina G, Viggiano A, De Luca V, Messina A, Chieffi S, et al. (2013) Hormonal 
changes in menopause and orexin-a action. Obstet Gynecol Int 2013: 209812.

10. Mieda M, Willie JT, Hara J, Sinton CM, Sakurai T, et al. (2004) Orexin peptides prevent cataplexy and improve wakefulness in an orexin neuron-ablated model of narcolepsy in mice. Proc Natl Acad Sci U S A 101: 4649-4654.

11. Funato H, Tsai AL, Willie JT, Kisanuki Y, Williams SC, et al. (2009) Enhanced orexin receptor-2 signaling prevents diet-induced obesity and improves leptin sensitivity. Cell Metab 9: 64-76.

12. de Lecea L, Kilduff TS, Peyron C, Gao X, Foye PE, et al. (1998) The hypocretins: hypothalamus-specific peptides with neuroexcitatory activity. Proc Natl Acad Sci U S A 95: 322-327.

13. Berthoud HR (2005) Brain, appetite and obesity. Physiol Behav 85: 1-2.

14. Eggermann E, Bayer L, Serafin M, Saint-Mleux B, Bernheim L, et al. (2003) The wake-promoting hypocretin-orexin neurons are in an intrinsic state of membrane depolarization. J Neurosci 23: 1557-1562.

15. Burt J, Alberto CO, Parsons MP, Hirasawa M (2011) Local network regulation of orexin neurons in the lateral hypothalamus. Am J Physiol Regul Integr Comp Physiol 301: R572-580.

16. Larsson KP, Peltonen HM, Bart G, Louhivuori LM, Penttonen A, et al. (2005) Orexin-A-induced $\mathrm{Ca} 2+$ entry: evidence for involvement of trpc channels and protein kinase $C$ regulation. J Biol Chem 280: 1771-1781.

17. Hoang QV, Bajic D, Yanagisawa M, Nakajima S, Nakajima Y (2003) Effects of orexin (hypocretin) on GIRK channels. J Neurophysiol 90: 693-702.

18. Hoang QV, Zhao P, Nakajima S, Nakajima Y (2004) Orexin (hypocretin) effects on constitutively active inward rectifier $\mathrm{K}+$ channels in cultured nucleus basalis neurons. J Neurophysiol 92: 3183-3191.

19. Samson WK, Taylor MM, Follwell M, Ferguson AV (2002) Orexin actions in hypothalamic paraventricular nucleus: Physiological consequences and cellular correlates. Regul Pept 104:97-103.

20. Liu RJ, van den Pol AN, Aghajanian GK (2002) Hypocretins (orexins) regulate serotonin neurons in the dorsal raphe nucleus by excitatory direct and inhibitory indirect actions. J Neurosci 22: 9453-9464.

21. Monda M, Viggiano A, Mondola $P$, De Luca V (2001) Inhibition of prostaglandin synthesis reduces hyperthermic reactions induced by hypocretin-1/orexin $A$. Brain Res 909: 68-74.

22. Kukkonen JP, Holmqvist T, Ammoun S, Akerman KE (2002) Functions of the orexinergic/hypocretinergic system. Am J Physiol Cell Physiol 283: C15671591.

23. Cannon B, Nedergaard J (2004) Brown adipose tissue: function and physiological significance. Physiol Rev 84: 277-359.

24. Morrison SF (2004) Central pathways controlling brown adipose tissue thermogenesis. News Physiol Sci 19: 67-74.

25. van den Pol AN (1999) Hypothalamic hypocretin (orexin): robust innervation of the spinal cord. J Neurosci 19: 3171-3182.

26. Ogden CL, Carroll MD, Curtin LR, McDowell MA, Tabak CJ, et al. (2006) Prevalence of overweight and obesity in the United States, 1999-2004. JAMA 295: 1549-1555.

27. Flegal KM, Carroll MD, Ogden CL, Curtin LR (2010) Prevalence and trends in obesity among US adults, 1999-2008. JAMA 303: 235-241.

28. Must A, Spadano J, Coakley EH, Field AE, Colditz G, et al. (1999) The disease burden associated with overweight and obesity. JAMA 282: 1523-1529.

29. Mustelin L, Silventoinen K, Pietiläinen K, Rissanen A, Kaprio J (2009) Physical activity reduces the influence of genetic effects on $\mathrm{BMI}$ and waist circumference: a study in young adult twins. Int J Obes (Lond) 33: 29-36.

30. Hamilton MT, Hamilton DG, Zderic TW (2007) Role of low energy expenditure and sitting in obesity, metabolic syndrome, type 2 diabetes, and cardiovascular disease. Diabetes 56: 2655-2667

31. Levine JA, Kotz CM (2005) NEAT--non-exercise activity thermogenesisegocentric \& geocentric environmental factors vs. biological regulation. Acta Physiol Scand 184: 309-318.

32. Levine JA, Eberhardt NL, Jensen MD (1999) Role of nonexercise activity thermogenesis in resistance to fat gain in humans. Science 283: 212-214.

33. Levine JA, Lanningham-Foster LM, McCrady SK, Krizan AC, Olson LR, et al.
(2005) Interindividual variation in posture allocation: possible role in human obesity. Science 307 : 584-586.

34. Kotz CM, Wang C, Teske JA, Thorpe AJ, Novak CM, et al. (2006) Orexin A mediation of time spent moving in rats: neural mechanisms. Neuroscience 142: $29-36$.

35. Garland T Jr, Schutz H, Chappell MA, Keeney BK, Meek TH, et al. (2011) The biological control of voluntary exercise, spontaneous physical activity and daily energy expenditure in relation to obesity: human and rodent perspectives. J Exp Biol 214: 206-229.

36. Messina G, De Luca V, Viggiano A, Ascione A, lannaccone T, et al. (2013) Autonomic nervous system in the control of energy balance and body weight personal contributions. Neurol Res Int 2013: 639280.

37. Messina G, Vicidomini C, Viggiano A, Tafuri D, Cozza V, et al. (2012) Enhanced parasympathetic activity of sportive women is paradoxically associated to enhanced resting energy expenditure. Auton Neurosci 169: 102-106.

38. De Luca V, Viggiano E, Messina G, Viggiano A, Borlido C, et al. (2008) Peripheral amino Acid levels in schizophrenia and antipsychotic treatment. Psychiatry Investig 5: 203-208.

39. Viggiano A, Nicodemo U, Viggiano E, Messina G, Viggiano A, et al. (2010) Mastication overload causes an increase in $\mathrm{O} 2$ - production into the subnucleus oralis of the spinal trigeminal nucleus. Neuroscience 166: 416-421.

40. Monda M, Messina G, Mangoni C, De Luca B (2008) Resting energy expenditure and fat-free mass do not decline during aging in severely obese women. Clin Nutr 27: 657-659.

41. Viggiano A, Vicidomini C, Monda M, Carleo D, Carleo R, et al. (2009) Fast and low-cost analysis of heart rate variability reveals vegetative alterations in noncomplicated diabetic patients. J Diabetes Complications 23:119-123.

42. Monda M, Messina G, Vicidomini C, Viggiano A, Mangoni C, et al. (2006) Activity of autonomic nervous system is related to body weight in pre-menopausal, but not in post-menopausal women. Nutr Neurosci 9: 141-145.

43. Jenkins JB, Omori T, Guan Z, Vgontzas AN, Bixler EO, et al. (2006) Sleep is increased in mice with obesity induced by high-fat food. Physiol Behav 87: 255-262.

44. Bronský J, Nedvídková J, Zamrazilová H, Pechová M, Chada M, et al. (2007) Dynamic changes of orexin $A$ and leptin in obese children during body weight reduction. Physiol Res 56: 89-96.

45. Kok SW, Meinders AE, Overeem S, Lammers GJ, Roelfsema F, et al. (2002 Reduction of plasma leptin levels and loss of its circadian rhythmicity in hypocretin (orexin)-deficient narcoleptic humans. J Clin Endocrinol Metab 87: 805-809.

46. Levin BE, Hogan S, Sullivan AC (1989) Initiation and perpetuation of obesity and obesity resistance in rats. Am J Physiol 256: R766-771.

47. Kotz CM, Teske JA, Billington CJ (2008) Neuroregulation of nonexercise activity thermogenesis and obesity resistance. Am J Physiol Regul Integr Comp Physiol 294: R699-710.

48. George O, Parducz A, Dupret D, Kharouby M, Le Moal M, et al. (2006) Smaddependent alterations of PPT cholinergic neurons as a pathophysiological mechanism of age-related sleep-dependent memory impairments. Neurobiol Aging 27: 1848-1858.

49. Lubkin M, Stricker-Krongrad A (1998) Independent feeding and metabolic actions of orexins in mice. Biochem Biophys Res Commun 253: 241-245.

50. Sweet DC, Levine AS, Billington CJ, Kotz CM (1999) Feeding response to central orexins. Brain Res 821: 535-538.

51. Monda M, Messina G, Scognamiglio I, Lombardi A, Martin GA, et al. (2014) Short-term diet and moderate exercise in young overweight men modulate cardiocyte and hepatocarcinoma survival by oxidative stress. Oxid Med Cell Longev 2014: 131024

52. Di Bernardo G, Messina G, Capasso S, Del Gaudio S, Cipollaro M, et al. (2014) Sera of overweight people promote in vitro adipocyte differentiation of bone marrow stromal cells. Stem Cell Res Ther 5: 4.

53. Esposito M, Serpe FP, Diletti G, Messina G, Scortichini G, La Rocca C, Bald L, Amorena M, Monda M (2014) Serum levels of polychlorinated dibenzo-pdioxins, polychlorinated dibenzofurans and polychlorinated biphenyls in a population living in the Naples area, southern Italy. Chemosphere 94:62-69. 
Citation: Messina G, Monda V, Moscatelli F, Valenzano AA, Monda G, et al. (2015) Role of Orexin system in obesity. Biol Med (Aligarh) 7: 248. doi: 10.4172/0974-8369.1000248

Page 6 of 6

54. Kiwaki K, Kotz CM, Wang C, Lanningham-Foster L, Levine JA (2004) Orexin A (hypocretin 1) injected into hypothalamic paraventricular nucleus and spontaneous physical activity in rats. Am J Physiol Endocrinol Metab 286 E551-559.

55. Monda M, Viggiano A, Viggiano A, Viggiano E, Messina G, et al. (2007) Sympathetic and hyperthermic reactions by orexin $A$ : role of cerebral catecholaminergic neurons. Regul Pept 139: 39-44.

56. Monda M, Viggiano A, Viggiano A, Viggiano E, Messina G, Tafuri D DL V. (2006) Quetiapine lowers sympathetic and hyperthermic reactions due to cerebral injection of orexin A.Neuropeptides 40:357-363.

57. Ricci MR, Levin BE (2003) Ontogeny of diet-induced obesity in selectively bred Sprague-Dawley rats. Am J Physiol Regul Integr Comp Physiol 285: R610-R618.

58. Monda M, Viggiano A, Viggiano A, Fuccio F, De Luca V (2004) Injection of orexin $A$ into the diagonal band of Broca induces sympathetic and hyperthermic reactions. Brain Res 1018: 265-271.

59. Monda M, Amaro S, Sullo A, De Luca B (1994) Posterior hypothalamic activity and cortical control during the PGE1 hyperthermia. Neuroreport 6: 135-139.

60. Monda M, Pittman QJ (1993) Cortical spreading depression blocks prostaglandin E1 and endotoxin fever in rats. Am J Physiol 264: R456-459.

61. Monda M, Amaro S, Sullo A, De Luca B (1995) Injection of muscimol in the posterior hypothalamus reduces the PGE1-hyperthermia in the rat. Brain Res Bull 37: 575-580.

62. Maclean IM, Wilson RJ (2011) Recent ecological responses to climate change support predictions of high extinction risk. Proc Natl Acad Sci U S A 108: 12337-12342.

63. Viggiano A, Chieffi S, Tafuri D, Messina G, Monda M, et al. (2014) Laterality of a second player position affects lateral deviation of basketball shooting. J Sports Sci 32: 46-52.

64. Zurlo F, Ferraro RT, Fontvielle AM, Rising R, Bogardus C, et al. (1992) Spontaneous physical activity and obesity: cross-sectional and longitudinal studies in Pima Indians. Am J Physiol 263: E296-300.

65. Novak CM, Zhang M, Levine JA (2007) Sensitivity of the hypothalamic paraventricular nucleus to the locomotor-activating effects of neuromedin $\mathrm{U}$ in obesity. Brain Res 1169: 57-68. 